\title{
Ventilation during cardiopulmonary resuscitation in children: a survey on clinical practice
}

\author{
Rafael González, Lázaro Pascual, Alexandra Sava, Sara Tolón, Javier Urbano, Jesus \\ López-Herce \\ Madrid, Spain
}

Background: This study aimed to investigate the ventilation practice during cardiopulmonary resuscitation (CPR) and after return of spontaneous circulation (ROSC) in children.

Methods: An online survey of CPR practices was designed and sent to healthcare professionals treating children.

Results: A total of $\mathbf{4 7 7}$ healthcare professionals from 46 countries responded to this survey; $92.7 \%$ were physicians and $64.2 \%$ worked in pediatric intensive care units. Specific CPR guidelines were used by $97.7 \%$ of respondents. The respiratory rate most frequently used for children over 12 months was 13 to 20 respirations per minute (rpm) $(46 \%$ in intubated and $41.8 \%$ in non-intubated). For infants under 12 months, the most frequently used respiratory rate was 21 to $30 \mathrm{rpm}$ in intubated patients $(37.3 \%)$ : in non-intubated infants, 13 to $20 \mathrm{rpm}(26.5 \%)$ and 21 to $30 \mathrm{rpm}(26.5 \%)$ were used with the same frequency. In North America, the respiratory rate most widely used was 7 to $12 \mathrm{rpm}$; higher rates (13 to $20 \mathrm{rpm}$ and 21 to $30 \mathrm{rpm}$ ) were used in Europe and Latin America $(P<0.001)$. After ROSC, no significant differences in the respiratory rates used were found between the continents. More than $40 \%$ of healthcare professionals had a target oxygen saturation below $94 \%$; more than $10 \%$ used a target arterial $\mathrm{PCO}_{2}$ below $35 \mathrm{mmHg}$ and more than $13 \%$ above $45 \mathrm{mmHg}$.

Conclusion: There is considerable variation in the management of ventilation of children in cardiac arrest,

Author Affiliations: Pediatric Intensive Care Department, Gregorio Marañón General University Hospital, School of Medicine, Complutense University of Madrid, Madrid, Spain (González R, Pascual L, Sava A, Tolón S, Urbano J, López-Herce J)

Corresponding Author: Jesus López-Herce, PhD, MD, Pediatric Intensive Care Department, Gregorio Marañón General University Hospital, Dr Castelo 47, Madrid 28009, Spain (Tel: 915290308; Fax: 915868018; Email: pielvi@hotmail.com)

doi: 10.1007/s12519-017-0061-2

(C)Children's Hospital, Zhejiang University School of Medicine, China and Springer-Verlag Berlin Heidelberg 2017. All rights reserved. and international recommendations are not being followed in a high percentage of cases.

World J Pediatr 2017;13(6):544-550

Key words: cardiopulmonary resuscitation; resuscitation; ventilation

\section{Introduction}

Pardiac arrest has a very high mortality in children, and survivors can present major neurological sequelae. ${ }^{[1,2]}$ One of the most important measures aimed at reducing mortality is early cardiopulmonary resuscitation $(\mathrm{CPR})$, and immediate action with appropriate CPR maneuvers is crucial. ${ }^{[3,4]}$

Ventilation is an essential maneuver of CPR in children; ${ }^{[3,4]}$ it is more important than in adults as a high percentage of cardiac arrests in children (between $30 \%$ and $70 \%$ ) are of respiratory origin. ${ }^{[1,2]}$

At the present time, the recommended compressionto-ventilation ratio for basic bystander CPR is 30:2, both for adults and for children; this is equivalent to a respiratory rate of 6 artificial breaths per minute (rpm). If the resuscitator is a healthcare professional, the European Resuscitation Council (ERC) recommends a $15: 2$ ratio in children, equivalent to about $12 \mathrm{rpm}^{\left[{ }^{3]}\right.}$ In advanced CPR, after intubation of the child, a respiratory rate of 10 to $12 \mathrm{rpm}$ is recommended until the return of spontaneous circulation (ROSC). ${ }^{[3,4]}$ However, there is insufficient evidence to determine the most appropriate respiratory rate during $\mathrm{CPR}$ and after $\mathrm{ROSC}$, and recommendations are based purely on studies in adults.

The importance of defining the respiratory rate during CPR and the appropriate compression-to-ventilation ratio derives from the increased risk of mortality associated with both hypo- and hyperventilation, as well as a higher risk of neurological sequelae among survivors. ${ }^{[5-10]}$

A number of experimental studies in adult animal models have compared distinct ratios, from cardiac massage alone, without ventilation, ${ }^{[11,12]}$ to ventilation with different respiratory rates. ${ }^{[10,12-15]}$ 
Some studies found better results with continuous chest compressions, ${ }^{[12,14]}$ others with higher respiratory rate ${ }^{[10,13]}$ and others did not find differences between several respiratory rates. ${ }^{[15]}$ On the other hand, some clinical studies in childre ${ }^{[16]}$ and in pediatric animal models ${ }^{[17-19]}$ have demonstrated the benefit of ventilatory support and of using higher respiratory frequencies than those recommended, observing better oxygenation without any negative effects on the hemodynamic status.

Furthermore, it is unclear what respiratory rate is actually used during CPR in children in clinical practice. Some observational studies have found that resuscitators use higher respiratory rates than those recommended, ${ }^{[20]}$ but repercussions on the outcome of CPR are unknown.

The objective of this study was to describe ventilatory practice during CPR in children and during the stabilization period after ROSC and to determine whether this practice adheres to international guidelines.

\section{Methods}

A multicentre survey was designed. A 38-item questionnaire was drafted on various aspects of ventilation (devices available for ventilation, respiratory rate during CPR and ventilation mode and respiratory parameters during the stabilization period after ROSC in children). Several data as respiratory rates were divided into predefined ranges in the questionnaire. We have followed the international resuscitation recommendations that divided children in three ages: newborn, infant (under one year) and children (more than one year). ${ }^{[3,4]}$ The questionnaire was drawn up in Spanish and subsequently translated into English. To facilitate online anonymity, the questionnaire was uploaded to the Google Forms Tool (Google, Mountain View, California, USA) (Supplemental Questionnaire).

A link to the questionnaire was sent by email to a number of scientific societies: the Spanish Society for Pediatric and Neonatal Intensive Care, ERC, the World Federation of Pediatric Intensive Care Societies, the Spanish Pediatric and Neonatal Cardiopulmonary Resuscitation Group and the Spanish Society of Pediatric Intensive Care. These societies passed the questionnaire to their members and to other healthcare professionals who could be involved in pediatric CPR.

The data obtained from the survey were analyzed using the IBM SPSS Statistics for OsX, version 20.0 (IBM Corp., Armonk, New York). A descriptive study was performed expressing frequencies in absolute values and percentages. The Chi-square test and Fischer test were employed to compare frequencies between continents. Results for both global and continent-paired comparison are shown in the text when comparing respiratory rates used during resuscitation. A $P$ value less than 0.05 was considered statistically significant. Comparisons with Africa and Oceania were not possible because of the very low number of replies from those continents.

\section{Results \\ Characteristics of the study population}

We received 477 replies from 46 countries; 243 questionnaires (50.9\%) came from Europe, 182 of those from Spain, $111(23.2 \%)$ from Central and South America, 86 (18\%) from North America, 30 (6.3\%) from Asia, $5(1 \%)$ from Africa and $2(0.4 \%)$ from Oceania. The majority of the respondents $(74.4 \%)$ were between 30 and 50 years of age and $47 \%$ were women. The study population comprised $92.7 \%$ doctors, $6.1 \%$ nursing staff and $1.2 \%$ other healthcare professionals (paramedics); $79.5 \%$ worked in a university hospital and $64.2 \%$ worked in pediatric intensive care units.

\section{General comments on CPR practice}

In their daily clinical practice, $98.7 \%$ of the professionals cared for children at risk of cardiac arrest. In the previous year, more than $70 \%$ had attended 10 or fewer arrests and $50 \%$ attended 5 or fewer cardiac arrests each year. CPR guidelines were followed by $97.7 \%$ of the respondents in their respective units: $47.6 \%$ of them used the American Heart Association (AHA) guidelines (North America, Central and South America, and Asia), and 31.8\% used the ERC guidelines (in Europe). Specific national guidelines were used by $17.2 \%$ of respondents, and guidelines drawn up by the individual units were used in $3.4 \%$ of cases.

\section{Devices available for ventilation during CPR}

The devices available for performing ventilation during CPR included a self-inflating manual ventilation bag (95.8\%), an anaesthesia bag (51\%), a hospital respirator with various modes of ventilation $(83 \%)$, a portable adult volume-controlled respirator in $51 \%$, a portable

Table 1. Frequency of different respiratory rates used during cardiopulmonary resuscitation according to age and intubation, $\%$

\begin{tabular}{lcccc}
\hline $\begin{array}{l}\text { Respiratory rate } \\
\text { during CPR (rpm) }\end{array}$ & \multicolumn{2}{c}{ Age under 12 mon } & \multicolumn{2}{c}{ Age over 12 mon } \\
\cline { 2 - 4 } \cline { 5 - 6 } & Intubated & Non-intubated & Intubated & Non-intubated \\
\hline 6 & 1.9 & 4.5 & 4.2 & 8.7 \\
$7-12$ & 16.7 & 22.9 & 27.3 & 32.3 \\
$13-20$ & 22.5 & 26.5 & 46.0 & 41.8 \\
$21-30$ & 37.3 & 26.5 & 12.9 & 10.6 \\
$>30$ & 12.9 & 13.4 & 0.4 & 1.5 \\
According to & 8.7 & 6.2 & 9.1 & 5.1 \\
pathology & & &
\end{tabular}

CPR: cardiopulmonary resuscitation; rpm: respirations per minute. 
ventilator with modes for ventilation in $67.9 \%$ and an anaesthetic machine in $27.5 \%$.

\section{Respiratory management during CPR in children}

Ventilation during CPR was performed by $98.1 \%$ of the professionals surveyed. In some continents (North America: $32.9 \%$; Asia: $40 \%$ ), respondents stated that they sometimes performed CPR in children exclusively with chest compressions, without ventilation.

Table 1 shows the respiratory rates used during CPR in intubated and non-intubated patients, according to patient age (under or over 12 months). Considerable differences were observed, but the respiratory rate most frequently used was 13 to $20 \mathrm{rpm}$, both in intubated and in non-intubated patients.

In non-intubated patients, the respiratory rate recommended in international guidelines varies between 6 and $12 \mathrm{rpm}$ (depending on whether a 30:2 or 15:2 compression-to-ventilation ratio is used). Only $27.4 \%$ of respondents used this respiratory rate in children under 12 months of age, and $41 \%$ in older children. Table 2 presents a comparison of the respiratory rates used during cardiac arrest in nonintubated children according to the continent of residence. In North America, the most frequently used respiratory rate was 7 to $12 \mathrm{rpm}$, whereas higher rates were more common in Europe and Central and South

Table 2. Intercontinental comparison of the respiratory rates used in non-intubated patients

\begin{tabular}{|c|c|c|c|c|c|}
\hline \multirow[b]{2}{*}{ Age } & \multirow{2}{*}{$\begin{array}{l}\text { Respiratory } \\
\text { rate (rpm) }\end{array}$} & \multicolumn{4}{|c|}{ Continent, \% } \\
\hline & & Europe & North America & $\begin{array}{l}\text { Central and South } \\
\text { America }\end{array}$ & Asia \\
\hline \multirow[t]{6}{*}{$<12$ mon } & 6 & 2.1 & 4.7 & 9.1 & 6.9 \\
\hline & $7-12$ & 17.9 & 37.6 & 22.7 & 24.1 \\
\hline & $13-20$ & 24.6 & 25.9 & 30.0 & 31.0 \\
\hline & $21-30$ & 34.6 & 12.9 & 20.9 & 20.7 \\
\hline & $>30$ & 15.8 & 4.7 & 15.5 & 13.8 \\
\hline & $\begin{array}{l}\text { According to } \\
\text { pathology }\end{array}$ & 5.0 & 14.1 & 1.8 & 3.4 \\
\hline \multirow[t]{6}{*}{$>12$ mon } & 6 & 5.4 & 11.8 & 14.5 & 6.7 \\
\hline & $7-12$ & 26.8 & 47.1 & 30.0 & 46.7 \\
\hline & $13-20$ & 49.0 & 23.5 & 45.5 & 23.3 \\
\hline & $21-30$ & 13.0 & 5.9 & 8.2 & 13.3 \\
\hline & $>30$ & 1.7 & 0 & 0.9 & 6.7 \\
\hline & $\begin{array}{l}\text { According to } \\
\text { pathology }\end{array}$ & 4.2 & 11.8 & 0.9 & 3.3 \\
\hline
\end{tabular}

Global comparison: $P<0.001$ for both children over and under 12 months. Europe vs. North America: $P<0.001$ in children over and under 12 months; Europe vs. Central and South America: $P=0.030$ in children over 12 months and $P=0.005$ in infants under 12 months; Europe $v s$. Asia: $P=0.061$ in children over 12 months and $P=0.419$ in infants under 12 months; North America vs. Central and South America: $P=0.001$ in children over 12 months and $P=0.001$ in infants under 12 months; North America vs. Asia: $P=0.093$ in children over 12 months and $P=0.211$ in infants under 12 months; Central and South America vs. Asia: $P=0.047$ in children over 12 months and $P=0.993$ in infants under 12 months. rpm: respirations per minute.
America (13 to $20 \mathrm{rpm}$ or 21 to $30 \mathrm{rpm})(P<0.001)$.

Bag-mask ventilation coordinated with chest compressions was used by $87.2 \%$ in non-intubated patients. A higher percentage of respondents in North America and Central and South America did not coordinate ventilations with chest compressions $(23.5 \%$ and $18.9 \%$, respectively) than in Europe $(6.6 \%)$, ( $P<0.001$ for both comparisons).

Chest compressions were interrupted by $67.3 \%$ of respondents in order to perform intubation. This percentage was higher in Europe (72.7\%) than in North America $(59.5 \%, P=0.028)$ or Central and South America (61.8\%, $P=0.046)$.

A manual self-inflating bag was used by $78.2 \%$ of respondents to perform ventilation during chest compressions in intubated children, a mechanical ventilator by $11.8 \%$, both devices by $2.3 \%$, an anaesthetic bag by $6.1 \%$ and other methods by $1.5 \%$.

In intubated patients, the respiratory rate recommended in international guidelines for use during CPR varies between 10 and $12 \mathrm{rpm}$. Only $16.7 \%$ of respondents used this rate in infants under a year old, and $27.3 \%$ in older children. The most commonly used respiratory rate in infants aged under 12 months was 21 to $30 \mathrm{rpm}(37.3 \%)$, and in older children was 13 to $20 \mathrm{rpm}(46 \%)$.

Table 3 shows a comparison of the respiratory rates used in intubated children in the different continents.

Table 3. Intercontinental comparison of respiratory rates used in intubated patients

\begin{tabular}{|c|c|c|c|c|c|}
\hline \multirow[b]{2}{*}{ Age } & \multirow{2}{*}{$\begin{array}{r}\text { Respiratory } \\
\text { rate (rpm) }\end{array}$} & \multicolumn{4}{|c|}{ Continent, \% } \\
\hline & & Europe & North America & $\begin{array}{l}\text { Central and South } \\
\text { America }\end{array}$ & Asia \\
\hline \multirow[t]{6}{*}{$<12$ mon } & & 1.3 & 3.5 & 2.7 & 0 \\
\hline & $7-12$ & 10.9 & 34.1 & 14.5 & 26.7 \\
\hline & $13-20$ & 19.2 & 18.8 & 30.0 & 26.7 \\
\hline & $21-30$ & 45.2 & 21.2 & 32.7 & 43.3 \\
\hline & $>30$ & 14.2 & 7.1 & 16.4 & 3.3 \\
\hline & $\begin{array}{l}\text { According to } \\
\text { pathology }\end{array}$ & 9.2 & 15.3 & 3.6 & 0 \\
\hline \multirow[t]{6}{*}{$>12$ mon } & & 3.4 & 9.4 & 3.6 & 0 \\
\hline & $7-12$ & 17.6 & 41.2 & 31.5 & 50.0 \\
\hline & $13-20$ & 55.0 & 22.4 & 47.7 & 36.7 \\
\hline & $21-30$ & 13.4 & 11.8 & 13.5 & 10.0 \\
\hline & $>30$ & 0.8 & 0 & 0 & 0 \\
\hline & $\begin{array}{l}\text { According to } \\
\text { pathology }\end{array}$ & 9.7 & 15.3 & 3.6 & 3.3 \\
\hline
\end{tabular}

Global comparison: $P<0.001$ for both children over and under 12 months. Europe vs. North America: $P<0.001$ in children over and under 12 months; Europe vs. Central and South America: $P=0.036$ in children over 12 months and $P=0.037$ in infants under 12 months; Europe $v s$. Asia: $P=0.004$ in children over 12 months and $P=0.041$ in infants under 12 months; North America vs. Central and South America: $P<0.001$ in children over and under 12 months; North America vs. Asia: $P=0.106$ in children over 12 months and $P=0.047$ in infants under 12 months; Central and South America vs. Asia: $P=0.376$ in children over 12 months and $P=0.172$ in infants under 12 months. rpm: respirations per minute. 
In North America, the most frequently used respiratory rate was 7 to $12 \mathrm{rpm}$, whereas higher respiratory rates were used in Europe and Central and South America (13 to $20 \mathrm{rpm}$ or 21 to $30 \mathrm{rpm})(P<0.001)$.

The respiratory rate during CPR continued to be higher in Europe than in North America when the comparison was performed after excluding the data from Spain (the country with the largest number of respondents; data not shown).

Professionals following AHA guidelines used lower respiratory rates than those applying the ERC guidelines, both in intubated and non-intubated patients and in children, older and younger than 12 months (Supplemental Table).

The most widely used fraction of inspired oxygen $\left(\mathrm{FiO}_{2}\right)$ during CPR was $100 \%$ (80.1\% of cases), with a target oxygen saturation over $90 \%$ was used in $97.5 \%$ of cases.

Table 4. Ventilation modes and parameters most widely used after recovery of spontaneous circulation

\begin{tabular}{|c|c|}
\hline Parameters & $\%$ \\
\hline \multicolumn{2}{|l|}{ Ventilation mode } \\
\hline Respirator not used & 3.9 \\
\hline Pressure-regulated volume control & 29.6 \\
\hline Pressure control & 24.4 \\
\hline Volume control & 15.1 \\
\hline According to the clinical situation & 26.8 \\
\hline \multicolumn{2}{|l|}{$\mathrm{PEEP}\left(\mathrm{cm} \mathrm{H}_{2} \mathrm{O}\right)$} \\
\hline 0 & 1.1 \\
\hline $1-5$ & 39.0 \\
\hline $6-10$ & 31.6 \\
\hline$>10$ & 0.4 \\
\hline According to the clinical situation & 27.9 \\
\hline \multicolumn{2}{|l|}{ Respiratory rate (rpm) } \\
\hline $8-10$ & 4.1 \\
\hline $11-15$ & 17.9 \\
\hline$>16$ & 30.1 \\
\hline According to the clinical situation & 47.8 \\
\hline \multicolumn{2}{|l|}{$\mathrm{FiO}_{2}, \%$} \\
\hline Based on $\mathrm{SatO}_{2}$ (pulse oxymetry) & 75.4 \\
\hline$<50$ & 6.5 \\
\hline $51-80$ & 6.1 \\
\hline $81-99$ & 7.4 \\
\hline 100 & 4.6 \\
\hline \multicolumn{2}{|l|}{ Target $\mathrm{EtCO}_{2}(\mathrm{mmHg})$} \\
\hline 30 & 2.1 \\
\hline $31-35$ & 8.2 \\
\hline $36-40$ & 44.7 \\
\hline $41-45$ & 31.9 \\
\hline $46-50$ & 10.1 \\
\hline $51-55$ & 2.6 \\
\hline $56-60$ & 0.5 \\
\hline \multicolumn{2}{|l|}{ Target $\mathrm{SatO}_{2}, \%$} \\
\hline $85^{\circ}$ & 1.7 \\
\hline 90 & 15.1 \\
\hline 92 & 24.3 \\
\hline 94 & 8.4 \\
\hline 96 & 26.4 \\
\hline$>96$ & 24.3 \\
\hline
\end{tabular}

Ventilation mode and respiratory parameters after recovery of spontaneous circulation

Table 4 shows the ventilation modes and parameters most widely used after ROSC. Pressure control and pressure-regulated volume control ventilation were the most widely used modes. Respiratory rate was generally determined according to the clinical situation, and peak end expiratory pressure was typically maintained between 1 and $5 \mathrm{~cm} \mathrm{H} \mathrm{H}_{2} \mathrm{O}$. The $\mathrm{FiO}_{2}$ was usually adjusted according to pulse oximetry. The most common target saturation was $96 \%$, but more than $40 \%$ of the respondents had a target saturation below 94\%. The most common target $\mathrm{CO}_{2}$ was between 35 and $40 \mathrm{mmHg}$, but more than $10 \%$ of respondents had a target $\mathrm{CO}_{2}$ below $35 \mathrm{mmHg}$ and more than $13 \%$ above $45 \mathrm{mmHg}$.

A comparison of the respiratory rates used after ROSC in the different continents is shown in Table 5. There were no significant differences between continents. However, professionals following AHA guidelines used a respiratory rate of 8 to $10 \mathrm{rpm}$ more commonly than those following the ERC guidelines (23.7\% vs. $11.3 \%)$ and were less likely to use a respiratory rate over 16 rpm $(18.8 \%$ vs. 36.8\%) $(P=0.001)$. Patient triggering was activated by $69.7 \%$ of respondents after ROSC. The parameter most widely used initially to monitor oxygenation was saturation $(77.9 \%)$, in $10.1 \%$ was the partial pressure of oxygen $\left(\mathrm{PO}_{2}\right)$ on blood gas analysis, and in $12 \%$ was the colour of the skin and mucosas. The $\mathrm{FiO}_{2}$ was adjusted according to pulse oximetry by $95.7 \%$ of respondents, and $80 \%$ changed the ventilator parameters according to capnography results.

The first blood gas sample was taken immediately after ROSC by $20 \%$ of respondents, at 5 to 10 minutes by $40.7 \%$, after 11 to 20 minutes by $18.9 \%$ and after more than 20 minutes by $12.4 \%$. The first X-ray was taken immediately after ROSC by $28.4 \%$ of the respondents, after an hour by $24.7 \%$, in the first 24 hours by $6.4 \%$ and according to the patient's clinical state by $40.6 \%$.

Table 5. Intercontinental comparison of respiratory rates after recovery of spontaneous circulation

\begin{tabular}{|c|c|c|c|c|}
\hline \multicolumn{5}{|c|}{ Resniratory rate Continent, \% } \\
\hline (rpm) & Europe & North America & $\begin{array}{l}\text { Central and South } \\
\text { America }\end{array}$ & Asia \\
\hline $\begin{array}{l}\text { According to } \\
\text { the situation }\end{array}$ & 49.1 & 50.6 & 43.9 & 42.9 \\
\hline $8-10$ & 3.4 & 1.2 & 7.5 & 7.1 \\
\hline $11-15$ & 16.2 & 18.5 & 18.7 & 25.0 \\
\hline$>16$ & 31.2 & 29.6 & 29.9 & 25.0 \\
\hline
\end{tabular}

Global comparison: $P=0.802$. Europe $v s$. North America: $P=0.738$; Europe vs. Central and South America: $P=0.348$; Europe vs. Asia: $P=0.347$; North America vs. Central and South America: $P=0.241$; North America vs. Asia: $P=0.323$; Central and South America vs. Asia: $P=0.888$. rpm: respirations per minute. 


\section{Discussion}

This is the first international study to analyze clinical practice criteria of healthcare professionals in respiratory management during CPR and after ROSC. Our study has analyzed a large number of responses from healthcare professionals from 46 countries, giving us a broad view of ventilatory practice during $\mathrm{CPR}$ in children.

More than $50 \%$ of the healthcare professionals who responded to the survey attended 5 or fewer cardiac arrests each year. The low frequency of arrest in children makes it difficult to perform clinical studies to compare the efficacy of distinct respiratory parameters during CPR.

Almost all healthcare professionals who responded stated that they followed the recommendations of the guidelines (AHA, ERC, or specific national guidelines); however, our dataed showed that respiratory management during CPR and after ROSC varies considerably and only a small number of clinicians follow international guidelines.

Although there is no evidence on which respiratory rate is most suitable during CPR in children, ${ }^{[20,21]}$ international guidelines recommend using between 6 and $12 \mathrm{rpm}$ in non-intubated children and between 10 and $12 \mathrm{rpm}$ after intubation. However, in our study we found a very high percentage of clinicians used a higher respiratory rate, particularly in infants under 12 months. These results coincide with the findings of some observational studies ${ }^{[20]}$ and highlight the importance of performing experimental and clinical studies to determine the most appropriate respiratory rate $^{[22]}$ and to evaluate the effect of hyperventilation and hypoventilation on pediatric CPR. Hypoventilation can produce hypoxemia and respiratory acidosis, with decreased survival and an increase in the rate of neurological sequelae among survivors. ${ }^{[5,7,8]}$ Some studies found that a low respiratory rate is associated with lower cerebral blood flow, low cerebral tissue $\mathrm{PO}_{2}$ and lower oxygen saturation in mixed venous blood. ${ }^{[10]}$ In addition, this produces a reduction in lung volume, which increases pulmonary vascular resistance and thus reduces pulmonary blood flow. ${ }^{[10]}$

Hypocapnia may affect vascular tone, affecting pulmonary and cerebral blood flow, blood volume and compartmental pressures. ${ }^{[23]}$ Hyperventilation during CPR has been associated with increased intrathoracic pressure and a lower coronary artery and cerebral perfusion pressure, leading to a lower survival. ${ }^{[9,10,24]}$ On the other hand, excessive time to ventilations could reduce the time and the quality of chest compressions.

Interestingly, we found that the respiratory rate used in Europe was higher than that used in North America, perhaps because the CPR algorithm in the latest American recommendations has been inverted, placing greater importance on chest compressions than on ventilation. ${ }^{[4]}$ In America, a higher percentage of respondents sometimes performed CPR without ventilation, even though experimental studies and clinical studies in children have demonstrated that CPR with ventilation and massage achieved better results than CPR with cardiac massage alone. ${ }^{[16,18,19]}$

In non-intubated patients, the guidelines recommend performing ventilation coordinated with chest compression, and this is applied more frequently in Europe than in North America or Central and South America.

Regarding oxygen therapy, the majority of respondents used a $\mathrm{FiO}_{2}$ of 1.0, in accordance with current recommendations in children and in adults.

After ROSC, the majority of respondents adjusted ventilation to the patient's clinical state, as no universally accepted ventilatory modes or parameters exist. This situation can be explained by the lack of international recommendations on ventilation after ROSC..$^{[3,4]}$

Oxygen saturation recommended by the international guidelines after ROSC is between $94 \%$ and $98 \%,{ }^{[2]}$ as not only severe hypoxemia but also hyperoxia is associated with a higher risk of death after ROSC from cardiac arrest. ${ }^{[6,25,26]}$ However, in our survey, more than $40 \%$ of respondents described target saturation figures below 94\%.

A further reason for the recommendation for normoventilation after recovery from cardiac arrest in children is that both hypocapnia and hypercapnia are associated with a higher mortality. ${ }^{[6]}$ Despite this, $10 \%$ of respondents reported a target expiratory $\mathrm{CO}_{2}$ below $35 \mathrm{mmHg}$ and $13 \%$ above $45 \mathrm{mmHg}$, and this fact could have a negative effect on outcome. ${ }^{[6,24]}$

Our study has certain limitations. First, it is a survey and can only therefore reflect intention-to-treat, that is, what clinicians believe they perform during CPR. However, true clinical practice is often different from what clinicians think they do. In the clinical practice, it is very difficult to perform coordinated chest compressions and ventilations with a ventilation rate of 21-30 per minute. That would imply a chest compression rate of more than 200 per minute at a ratio of 15:2. Observational clinical studies are therefore needed to analyze actual management of ventilation during CPR and after ROSC in children.

Furthermore, this is an open survey, in which the identification of the participants was not verified and no limitations were placed on participation. These criteria facilitated the distribution of the survey and freedom when making replies, reflected by the large number of responses we received from around the world, but also made it impossible to control for bias that could affect the reliability of the responses. 
Survey was sent to pediatric societies, mainly with emergency and intensive practitioners. So neonatal resuscitation practices were not evaluated.

With respect to the comparison between continents, relevant numbers of responses were only obtained from Europe and America. The largest number of responses was from Spain, and this could have introduced bias into the study. However, the differences in the respiratory rates used during CPR and after ROSC in Europe and North America persisted when Spain was excluded from the analysis. The number of respondents in Africa and Oceania was insufficient to perform statistically valid comparisons. Thus, although our study presents a broad initial overview of ventilation practice during CPR in children and opens the door to further research, it cannot be taken as an accurate reflection of the true worldwide situation.

In conclusion, there is marked variability in ventilation management during cardiac arrest and after ROSC in the child. Although the majority of healthcare professionals state that they follow current international recommendations, compliance with these guidelines is low in clinical practice. A high percentage do not adhere to the recommendations of international guidelines and use higher respiratory rates than recommended during CPR or after ROSC, with target saturation levels below those recommended. It is important to reinforce training in ventilation practices, controlling the respiratory rate, in pediatric CPR courses and to develop prospective observational studies to investigate the optimal respiratory rate and practices of ventilation during CPR and after ROSC in children.

\section{Acknowledgements}

We would like to thank Ignacio Manrique of the Spanish Pediatric and Neonatal CPR Group, The Spanish Society of Pediatric Intensive Care, Vinay Nadkarni and Bettina von Dessauer, and The World Federation of Pediatric Intensive Care Societies for their assistance in distributing the survey.

Funding: The study was partially supported by a grant from the Spanish Health Institute Carlos III (PI12/01307) and by the Maternal and Child Health and Development Research Network [RETICS funded by the PN I+D+I 2013-2016 (Spain), ISCIIISub-Directorate General for Research Assessment and Promotion and the European Regional Development Fund (ERDF), ref. RD16/0022].

Ethical approval: Research procedures were performed in accordance with the Declaration of Helsinki. Ethical approval for the study was obtained from Gregorio Marañón General University Hospital Local Research Ethics Committee. Informed consent obtention was not required as no individual data from patients were used for the study.

Competing interest: Authors declare no conflict of interest.
Contributors: González R, Urbano J and López-Herce J contributed to concept and design, analysis and interpretation of data, and revising article critically for important intellectual content. Pascual L, Sava A and Tolón S contributed to acquisition of data, analysis and interpretation of data and drafting the article. All authors approved the final version to be published.

\section{References}

1 López-Herce J, Del Castillo J, Matamoros M, Cañadas S, Rodriguez-Calvo A, Cecchetti C, el al. Factors associated with mortality in pediatric in-hospital cardiac arrest: a prospective multicenter multinational observational study. Intensive Care Med 2013;39:309-318.

2 Moler FW, Meert K, Donaldson AE, Nadkarni V, Brilli RJ, Dalton HJ, et al. In-hospital versus out-of-hospital pediatric cardiac arrest: a multicenter cohort study. Crit Care Med 2009;37:2259-2267.

3 Maconochie IK, Bingham R, Eich C, López-Herce J, RodríguezNúñez A, Rajka T, et al. European Resuscitation Council guidelines for resuscitation 2015: section 6. Paediatric life support. Resuscitation 2015;95:223-248.

4 de Caen AR, Berg MD, Chameides L, Gooden CK, Hickey RW, Scott HF, et al. Part 12: Pediatric advanced life support: 2015 American Heart Association guidelines update for cardiopulmonary resuscitation and emergency cardiovascular care. Circulation 2015;132:S526-S542.

5 Henlin T, Michalek P, Tyll T, Hinds JD, Dobias M. Oxygenation, ventilation, and airway management in out-of-hospital cardiac arrest: a review. Biomed Res Int 2014;2014:376871.

6 Del Castillo J, López-Herce J, Matamoros M, Cañadas S, Rodriguez-Calvo A, Cechetti C, et al. Hyperoxia, hypocapnia and hypercapnia as outcome factors after cardiac arrest in children. Resuscitation 2012;83:1456-1461.

7 Yannopoulos D, Matsuura T, McKnite S, Goodman N, Idris A, Tang W, et al. No assisted ventilation cardiopulmonary resuscitation and 24-hour neurological outcomes in a porcine model of cardiac arrest. Crit Care Med 2010;38:254-260.

8 Idris AH, Wenzel V, Becker LB, Banner MJ, Orban DJ. Does hypoxia or hypercarbia independently affect resuscitation from cardiac arrest? Chest 1955;108:522-528.

9 Aufderheide TP, Lurie KG. Death by hyperventilation: a common and life-threatening problem during cardiopulmonary resuscitation. Crit Care Med 2004;32:S345-S351.

10 Lurie KG, Yannopoulos D, McKnite SH, Herman ML, Idris AH, Nadkarni VM, et al. Comparison of a 10-breaths-per-minute versus a 2-breaths-per-minute strategy during cardiopulmonary resuscitation in a porcine model of cardiac arrest. Respir Care 2008;53:862-870.

11 Schmölzer GM, O'Reilly M, Labossiere J, Lee TF, Cowan S, Nicoll $\mathrm{J}$, et al. 3:1 compression to ventilation ratio versus continuous chest compression with asynchronous ventilation in a porcine model of neonatal resuscitation. Resuscitation 2014;85:270-275.

12 Wang S, Li C, Ji X, Yang L, Su Z, Wu J. Effect of continuous compressions and 30:2 cardiopulmonary resuscitation on global ventilation/perfusion values during resuscitation in a porcine model. Crit Care Med 2010;38:2024-2030.

13 Kill C, Torossian A, Freisburger C, Dworok S, Massmann M, Nohl T, et al. Basic life support with four different compression/ ventilation ratios in a pig model: the need for ventilation. Resuscitation 2009;80:1060-1065. 
14 Sanders AB, Kern KB, Berg RA, Hilwig RW, Heidenrich J, Ewy GA. Survival and neurologic outcome after cardiopulmonary resuscitation with four different chest compression-ventilation ratios. Ann Emerg Med 2002;40:553-562.

15 Hwang SO, Kim SH, Kim H, Jang YS, Zhao PG, Lee KH, et al. Comparison of 15:1, 15:2, and 30:2 compression-to-ventilation ratios for cardiopulmonary resuscitation in acanine model of a simulated, witnessed cardiac arrest. Acad Emerg Med 2008;15: 183-189.

16 Kitamura T, Iwami T, Kawamura T, Nagao K, Tanaka H, Nadkarni VM, et al. Conventional and chest-compression-only cardiopulmonary resuscitation by bystanders for children who have out-of-hospital cardiac arrests: a prospective, nationwide, population-based cohort study. Lancet 2010;375:1347-1354.

17 López-Herce J, Fernández B, Urbano J, Mencía S, Solana MJ, Rodríguez-Núñez A, et al. Hemodynamic, respiratory, and perfusion parameters during asphyxia, resuscitation, and postresuscitation in a pediatric model of cardiac arrest. Intensive Care Med 2011;37:147-155.

18 Iglesias JM, López-Herce J, Urbano J, Solana MJ, Mencía S, Del Castillo J. Chest compressions versus ventilation plus chest compressions in a pediatric asphyxial cardiac arrest animal model. Intensive Care Med 2010;36:712-716.

19 Botran M, Lopez-Herce J, Urbano J, Solana MJ, Garcia A, Carrillo A. Chest compressions versus ventilation plus chest compressions: a randomized trial in a pediatric asphyxialcardiac arrest animal model. Intensive Care Med 2011;37:1873-1880.

20 McInnes AD, Sutton RM, Orioles A, Nishisaki A, Niles D, Abella BS, et al. The first quantitative report of ventilation rate during in-hospital resuscitation of older children and adolescents. Resuscitation 2011;82:1025-1029.
21 Bennett KS, Clark AE, Meert KL, Topjian AA, Schleien $\mathrm{CL}$, Shaffner DH, et al. Early oxygenation and ventilation measurements after pediatric cardiac arrest: lack of association with outcome. Crit Care Med 2013;41:1534-1542.

22 Yannopoulos D, Tang W, Roussos C, Aufderheide TP, Idris $\mathrm{AH}$, Lurie KG. Reducing ventilation frequency during cardiopulmonary resuscitation in a porcine model of cardiac arrest. Respir Care 2005;50:628-635.

23 Maconochie IK, de Caen AR, Aickin R, Atkins DL, Biarent D, Guerguerian AM, et al. Part 6: Pediatric basic life support and pediatric advanced life support: 2015 International Consensus on cardiopulmonary resuscitation and emergency cardiovascular care science with treatment recommendations. Resuscitation 2015;95:e147-e168.

24 López-Herce J, del Castillo J, Matamoros M, Canadas S, Rodriguez-Calvo A, Cecchetti C, et al. Post return of spontaneous circulation factors associated with mortality in pediatric in-hospital cardiac arrest: a prospective multicenter multinational observational study. Crit Care 2014;18:607.

25 Ferguson LP, Durward A, Tibby SM. Relationship between arterial partial oxygen pressure after resuscitation from cardiac arrest and mortality in children. Circulation 2012;126:335-342.

26 Guerra-Wallace MM, Casey FL 3rd, Bell MJ, Fink EL, Hickey RW. Hyperoxia and hypoxia in children resuscitated from cardiac arrest. Pediatr Crit Care Med 2013;14:e143-e148.

Received May 20, 2016

Accepted after revision November 4, 2016

(Supplementary information is linked to the online version of the paper on the World Journal of Pediatrics website) 